\title{
RBEP
}

\section{Formação escolar e prática docente de professoras das classes populares: reflexões a partir da análise de memoriais acadêmicos}

Regina Lúcia Cerqueira Dias ${ }^{\mathrm{I}, \text { II }}$

http://dx.doi.org/10.1590/S2176-6681/348713579

\section{Resumo}

Este artigo tem como objetivo investigar as trajetórias escolares e a prática docente de professoras pertencentes às camadas populares que atuam na educação infantil e nos primeiros anos do ensino fundamental. Procurar-se-á refletir, com base na análise de memoriais acadêmicos elaborados em 2009 por um grupo de alunas-professoras do último período do curso Normal Superior, acerca da formação escolar e da prática docente desses sujeitos. Devido ao espaço restrito deste artigo e à abrangência da temática, neste trabalho será descrita e analisada especialmente a trajetória escolar narrada por uma dessas professoras. Utilizou-se no estudo uma abordagem biográfica. Assiste-se, nos últimos anos, a um aumento no número de docentes oriundos dessas camadas sociais. O trabalho pretende contribuir para que possamos compreender melhor quem são essas professoras, suas particularidades. Acredita-se que tal conhecimento seja fundamental para orientar nossas práticas como formadores de docentes e

Universidade Federal Fluminense (UFF), Niterói, Rio de Janeiro, Brasil. E-mail: regcerdias@yahoo. com.br

II Doutora em Educação pela Universidade Federal de Minas Gerais (UFMG), Belo Horizonte, Minas Gerais, Brasil. 
repensar a estrutura curricular dos cursos que formam esses profissionais da educação.

Palavras-chave: formação escolar e prática docente; memoriais; professoras dos meios populares.

\section{Abstract \\ School education and teaching practice of teachers of popular classes: reflections based on the analysis of academic memorials}

This article aims to investigate educational trajectories and teaching practices of female teachers belonging to low-income social classes, who work in kindergartens and in the early grades of fundamental education. Based on the analysis of academic memorials produced in 2009 by a group of intern-teachers, taking the last year of the course in Licentiate, this study aims to reflect about school education and the teaching practices of these teachers. Due to the limited scope of this article and the extent of the topic, this work describes and analyzes the school life narrated by one of the teachers. The research used a biographical approach. Recently, we have witnessed an increase in the number of teachers coming from these social layers. The paper aims to contribute to a better understanding of who these teachers are and their particularities. It is believed that such knowledge is essential to guide our practices as teacher educators and to rethink the curriculum of courses concerning the education of teaching professionals.

Keywords: school education; teaching practice; memorials; low-income teachers.

\section{Introdução}

O presente estudo foi motivado pela minha experiência, em 2009, como orientadora de um grupo de sete alunas do último período do curso Normal Superior, que elaboraram memoriais como exigência parcial para a conclusão da graduação. Procurarei, neste texto, considerando essa importante modalidade de trabalho, refletir acerca da formação escolar e da prática docente de alunas-professoras pertencentes às camadas populares. Assistimos, nos últimos anos, a um aumento no número de docentes oriundos dessas camadas sociais. Este artigo pretende contribuir para que possamos compreender melhor quem são esses sujeitos e quais são suas particularidades, com base na análise de trajetórias escolares e pessoais, conhecimento fundamental para orientar nossas práticas como formadores de docentes e repensar a estrutura curricular dos cursos que formam esses profissionais. 
De acordo com Houle (2008), a abordagem biográfica adotada neste estudo, redescoberta no início dos anos 1970, foi de grande importância para a Sociologia, pois trouxe o sujeito de volta às investigações, as quais privilegiavam, até então, os processos sociais. O autor defende a relevância dessa abordagem, argumentando que, ao trabalharmos com a história da vida de um sujeito, estamos também investigando "o relato ou a história da vida em sociedade" (Houle, 2008, p. 320). Além da contribuição que os memoriais acadêmicos podem proporcionar aos formadores de professores, já que ampliam o conhecimento sobre os discentes, Souza (2008) ressalta a importância desse tipo de experiência com histórias de vida, biografias educativas e entrevistas narrativas em virtude de essas metodologias apresentarem uma possibilidade de superar a racionalidade técnica nesse campo.

A instituição escolar na qual lecionei a disciplina Sociologia da Educação e orientei trabalhos de conclusão da graduação é um instituto superior de educação, que pertencia a uma fundação, localizada na região metropolitana de Belo Horizonte. Em função disso, era mantida com recursos do Estado e com recursos próprios, situação que acarretava duas consequências. A primeira delas é que a instituição podia cobrar mensalidades bem inferiores às das outras instituições de ensino particular, de modo a atrair alunos oriundos das camadas populares, vindos de cidades próximas a Belo Horizonte, da região metropolitana e mesmo da capital, os quais passavam a ter também a oportunidade de cursarem o ensino superior. A segunda consequência é que a referida fundação, em relação a várias faculdades situadas na capital e em sua região metropolitana, podia remunerar bem os professores formadores e, dessa forma, atraía profissionais com uma boa formação acadêmica, entre os quais mestres e doutores, que compunham a maioria do seu corpo docente.

Quanto à estrutura dos memoriais, primeiramente foi solicitado às alunas-professoras ${ }^{1}$ que descrevessem, de forma resumida, suas infâncias e configurações familiares. Posteriormente, deveriam descrever reflexivamente suas vivências no mundo escolar: sucessos, fracassos, professores que as marcaram positivamente ou negativamente e estratégias utilizadas pelas famílias e por elas para permitir a continuação dos estudos. Em uma terceira etapa, as alunas discorreriam acerca da escolha do curso Normal Superior, o ingresso na faculdade, o impacto cultural sofrido - ou não - por elas, as dificuldades financeiras, emocionais e culturais e as principais mudanças no habitus. Foi solicitado, na última parte do memorial, um relato sobre as experiências de estágio e as possíveis modificações na prática docente, uma vez que todas ministravam aulas, na educação infantil ou nos primeiros anos do ensino fundamental. Permitiu-se que as reflexões sobre a trajetória acadêmica fossem elaboradas individualmente ou com colegas que as alunas escolhessem para partilhá-las.

Todas as alunas-professoras que orientei eram oriundas das classes populares. Em relação ao pertencimento social, é preciso discutir, mesmo
1 As sete alunas, que elaboraram os memoriais acadêmicos sob minha orientação, já exerciam o ofício de professor em escolas públicas e particulares de Belo Horizonte e da região metropolitana dessa capital no período anterior ao ingresso no curso Normal Superior e continuaram a lecionar durante a graduação. Portanto, exerciam concomitantemente os papéis de alunas e professoras. 
que sucintamente, o conceito de classe social. Thompson (1987) contribuiu significativamente para a compreensão do que caracteriza uma classe social ao mostrar que não é possível defini-la apenas mediante a posição que os indivíduos ocupam em relação aos meios de produção, uma vez que classe é uma formação econômica, mas também cultural, não sendo possível hierarquizá-la e nem tomá-la de forma rígida como o fazem alguns estudiosos. Bourdieu (2007) afirma que os gostos funcionam como marcadores de classe, sendo os estilos de vida produtos do habitus, conceito fundamental para o autor, que será explicitado posteriormente. Os agentes estariam distribuídos no espaço social de acordo com o peso relativo dos diferentes tipos de capital, econômico e cultural, que possuem. Portanto, as docentes orientadas pertencem originalmente às classes populares, tomando-se como referência para situá-las nesse grupo social as dimensões econômica e cultural. Os pais das professoras possuem uma reduzida escolaridade formal, uma vez que nenhum deles prosseguiu os estudos após o antigo curso primário. Economicamente, as profissões a que se dedicaram, como motorista de caminhão, agricultor, pedreiro ou, no caso das mães, servente, babá, costureira, não possibilitaram às famílias gozar de tranquilidade financeira. Todas as professoras relataram as inúmeras dificuldades econômicas enfrentadas por elas. O estilo de vida das famílias do grupo de professoras que elaboraram os memoriais, no que se refere ao lazer e aos gostos culturais, mostrou-se também como típico das classes populares.

Quanto ao pertencimento étnico-racial das docentes, cinco são brancas e duas são negras. Os pais das professoras, oriundos do meio rural, migraram para Belo Horizonte e região metropolitana em busca de melhores condições de vida e para que seus filhos pudessem estudar. A maioria dos estudantes do curso Normal Superior é composta por mulheres. Percebe-se, a partir da análise dos memoriais, que a decisão pelo curso Normal Superior foi influenciada pelo fato de o magistério ser uma profissão tradicionalmente reservada às mulheres, especialmente o seu exercício nas primeiras séries escolares.

A leitura dos memoriais revelou itinerários escolares extremamente acidentados e uma mobilização intensa dos sujeitos e seus familiares para alcançar longevidade escolar, uma vez que as alunas são provenientes das camadas populares. Para esse grupo de discentes e docentes - visto que a maioria já ministrava aulas antes de iniciar o curso -, chegar à faculdade, mesmo em um curso desprestigiado pela sociedade, representa um grande avanço. Procurarei refletir somente sobre a trajetória de uma estudanteprofessora, devido ao espaço restrito deste artigo e à abrangência da temática. A análise será feita à luz de teóricos como Pierre Bourdieu e Bernard Lahire, que tratam da escolarização das classes populares, e outros autores como Maurice Tardif e Carlos Marcelo, que se dedicam aos estudos sobre formação e prática docente. 


\section{Família, infância e trajetória escolar}

Helena, nome fictício da aluna cuja trajetória escolar será analisada, é negra e nasceu no interior do estado de Minas Gerais. Mais tarde, migrou com a família para Belo Horizonte, capital do estado, em busca de melhores condições de vida e possibilidades de longevidade escolar, fato muito comum no caminho trilhado pelas discentes do curso Normal Superior. É oriunda de uma família numerosa, composta por 12 filhos.

Segundo Bourdieu (1998), uma das estratégias utilizadas pelas famílias da classe média em busca de sucesso escolar para os filhos é o controle da fecundidade, o que ele denomina malthusianismo. A longevidade escolar de Helena, proveniente de família numerosa, membro das classes desfavorecidas, representa - apesar do percurso acidentado, como veremos mais adiante - uma vitória que contraria os dados estatísticos, de acordo com os estudos que focalizam o sucesso escolar dos indivíduos que compõem esse grupo social. O pai era lavrador, porém apaixonado pela mineração, e a mãe foi descrita como uma "doce criatura" que se mobilizava para auxiliar a comunidade em suas carências. Helena frequentou a escola do vilarejo nos primeiros anos escolares, tendo como professoras filhas de fazendeiros, as quais haviam concluído o curso primário na cidade. Em 1965, a família mudou-se para Belo Horizonte e os filhos foram matriculados em um grupo escolar. O início da vida escolar na capital, aguardado com ansiedade pela aluna, tornou-se uma grande frustração quando ela se deparou com a escola real, como se pode perceber na passagem a seguir:

\footnotetext{
No primeiro dia de aula, de uniforme novo, eu me sentia a mais importante de todas as criaturas do universo. Porém, a decepção não demorou. Lá estava eu dentro daquela escola tão grande, no meio de tantas crianças e ao mesmo tempo só. Tive muito medo, chorei, mas, com o tempo, me acostumei a essa rotina. Eu não gostava da escola. As carteiras de dois lugares enfileiradas, o quadro-negro cheio de letras, as cortinas de cor creme balançando levemente com o vento que entrava pela janela, um sussurro de crianças falando juntas, no caderno infinitos exercícios de coordenação motora: a, e, i, o, u. Cada vogal em uma linha, de uma ponta a outra, subindo e descendo; as tardes ficavam longas, o sono batia. Entre um cochilo e outro ouvia a lição: Marcelo fez um barco. Marcelo fez um barco de papel. Marcelo...
}

O resultado desse triste início da vida escolar na cidade grande foi decepcionante para ela. Em razão do rendimento muito fraco, a docente de Helena, como sentença final, aconselhou sua mãe a tirá-la da escola, pois não estaria preparada para estudar. Bourdieu (2003) afirma que o capital cultural sempre retorna às mãos do capital cultural, pois os bens simbólicos só podem ser apreendidos e possuídos por aqueles indivíduos que possuem o código que permita entendê-los. A entrada franca em uma exposição de pinturas não garantiria, por si só, o real acesso das classes populares a esse tipo de arte, pois elas não possuem as referências necessárias para um grande aproveitamento desse evento. Da mesma forma, permitir o acesso dos alunos das classes desfavorecidas à escola não garante uma verdadeira aprendizagem, pois há, segundo o autor, uma enorme distância entre a 
cultura veiculada nas instituições de ensino e a cultura dessas classes sociais. A história de Helena, com certeza, pode ser estendida a várias famílias brasileiras que migraram do interior para a cidade, em busca de ascensão social por meio de novas oportunidades de emprego e estudo para os filhos. Na década de 1970, o acesso às escolas começava a ser estendido a todo o conjunto da população do País, mas isso não significava - e ainda não significa - a permanência dos alunos das camadas desfavorecidas nessas instituições. Segundo o autor:

Pela prática de uma pedagogia implícita que exige a familiaridade prévia com a cultura dominante e que procede pela técnica de familiarização insensível, um sistema de ensino propõe um tipo de informação e de formação acessíveis exclusivamente àqueles sujeitos dotados do sistema de disposições que constitui a condição de êxito da transmissão e da inculcação da cultura. Eximindo-se de oferecer a todos implicitamente, quer exigir de todos uniformemente que tenham o que não lhes foi dado, a saber, sobretudo a competência linguística e cultural e a relação de intimidade com a cultura e com a linguagem, instrumentos que somente a educação familiar pode produzir quando transmite a cultura dominante. (Bourdieu, 2003, p. 306-307).

Apesar de o início da vida estudantil ter sido frustrante, Helena descreve com saudade um bonito encontro em sua trajetória com uma professora de outro grupo escolar, dona Marta, que a ensinou a ler e a escrever. A pobreza estrutural da escola era compensada pela criatividade da docente, que utilizava os recursos disponíveis nas redondezas para ensinar seus alunos.

Após a conclusão do curso primário, Helena fez o curso de admissão, na época obrigatório para ingressar no ginásio. O exame de admissão ao ginásio, instituído em 1931, perdurou até o ano de 1971. Tal exame era constituído por provas orais e escritas. Romanelli (2007), baseando-se na análise feita sobre a história da educação no Brasil, do período de 1930 a 1973, advoga a tese de que a expansão do ensino no País foi controlada pelo governo por meio da ação legal. De acordo com a autora, havia "um alto índice de seletividade, determinado, em parte, e isso é inegável, pela presença de dispositivos legais que estipularam um sistema de avaliação extremamente minucioso, rígido e exagerado." (Romanelli, 2007, p. 138). O exame de admissão feito por Helena compôs o sistema de avaliação por 40 anos e constituiu-se em mais uma das barreiras enfrentadas por ela em seu processo de escolarização. Ela estudou em uma escola de freiras que atendia principalmente alunas das classes favorecidas, mas que abria suas portas também para pessoas carentes. Durante um ano, Helena esteve imersa em um mundo totalmente diferente de tudo o que conhecera até então. Os hábitos dos docentes, as maneiras diversas de ensinar e a aparência das colegas foram descritos na passagem seguinte, que retrata de maneira mais intensa a diferença social tão forte em nosso País.

O curso tinha duração de um ano, em regime de semi-internato. Na parte da manhã ia para a sala de aula, à tarde para as oficinas de artes. No 
início tinha impressão de estar vivendo em outro mundo. Os professores tinham outros hábitos e uma maneira bem diferente de ensinar, muitos não explicavam a matéria mais de uma vez, e se a gente não aprendia, o azar era nosso. As colegas de classe eram bem diferentes de mim, começando pela aparência: pele boa, cabelos bem tratados, roupas e sapatos caros. Frequentavam um programa na TV Itacolomi, algumas até desfilavam. Na sala de aula, essa diferença era bem evidenciada. Formávamos dois grupos: as alunas internas e as "outras" do horário escolar. Por vir de uma escola muito pobre, eu tinha dificuldade para entender alguns conteúdos transmitidos. Apesar de estudar muito, nunca consegui alcançar o desempenho que as "outras" alunas apresentavam.

O trecho acima nos remete à questão dos obstáculos que os alunos desfavorecidos socialmente enfrentam na difícil tarefa de obter longevidade escolar, mesmo com a expansão do sistema educacional em vários países.

Forquin (1995) apresenta um resumo de várias pesquisas elaboradas nas décadas de 1960 e 1970 que, entre outros aspectos, relacionavam as desigualdades de acesso à educação, o sucesso escolar e a origem social dos alunos. As pesquisas revelaram, de um modo geral, que a origem dos estudantes tinha uma influência significativa nos mecanismos de orientação e seleção escolar nos Estados Unidos, na Inglaterra e na França. Tais estudos foram importantes, pois mostraram que a questão do desempenho escolar dos alunos não dependia exclusivamente dos "dons individuais", pressuposto defendido pelas análises funcionalistas. Para que um estudante da classe desfavorecida obtivesse sucesso escolar, ele deveria vencer inúmeros obstáculos, já que existiria uma barreira de discriminação social fortemente estruturada. Segundo o autor, "o fracasso escolar não se reparte aleatoriamente em relação à origem social dos alunos, mas atinge de forma muito mais maciça e regular as crianças dos meios populares" (Forquin, 1995, p. 81).

Segundo Bourdieu (1998), as famílias transmitem a seus filhos um certo capital cultural e um certo ethos. A noção de transmissão é fundamental para entender as desigualdades diante da escola. Esse tipo de capital age com mais força sobre as desigualdades que o capital econômico. Informações sobre o sistema e as trajetórias escolares, os saberes e os gostos relacionados à cultura dominante e a facilidade, a elegância e a riqueza no uso da linguagem padrão são as três dimensões do capital cultural escolarmente rentáveis. Quanto maior a proximidade cultural das crianças e de suas famílias em relação à cultura escolar, maiores se tornam as chances de sucesso. Poderíamos dizer que o aluno das classes populares tende a se sentir na escola como um estrangeiro que chega a um país sem saber sua língua, seus costumes, sua cultura. É exatamente a incômoda sensação de sentir-se estrangeira que se depreende da passagem citada anteriormente, de autoria da aluna; sentimento ainda mais intenso devido à diferença social em relação às colegas de sala oriundas das classes favorecidas.

Transcorrido o período vivenciado na instituição de ensino em questão, Helena ficou um ano sem estudar, pois não havia vaga para o curso ginasial na rede pública e sua família não tinha condições de custear seus estudos 
na rede particular, o que, segundo ela, gerou enorme frustração. Em sua análise sobre a história da educação brasileira no final da década de 1960 que corresponde, portanto, ao período vivenciado -, Romanelli (2007, p. 62) afirma que "se, de um lado, cresceram a procura da escola e as oportunidades educacionais, de outro lado a estrutura escolar não sofreu mudanças substanciais", ou seja, não ofereceu quantitativa e qualitativamente o ensino de que a sociedade tanto necessitava. Episódios semelhantes ocorreram em outros momentos da história escolar de Helena, causando interrupções que a angustiaram. Zago (2000) chama a atenção para a trajetória escolar acidentada, comum aos estudantes dos meios populares.

Segundo Bourdieu (1998), até os anos 1950 o sistema de ensino praticamente eliminava as classes desfavorecidas do ensino secundário na França. Com a implantação da escolarização obrigatória até os 16 anos, os alunos dessas classes conseguiram chegar a essa etapa. O autor afirma, no entanto, que as desigualdades não desapareceram nem diminuíram, somente foram adiadas. Essa maior longevidade escolar não trouxe nem o sucesso escolar nem o social, de modo que "os despossuídos perceberam progressivamente as funções conservadoras da Escola libertadora" (Bourdieu, 1998, p. 220).

No caso brasileiro, ainda hoje as desigualdades educacionais persistem, ainda que o acesso ao ensino fundamental esteja caminhando para a universalização e haja, segundo Zago (2012, p. 133),

[...] uma redução pequena, mas gradativa, de diversas desigualdades (entre elas, as taxas da população não escolarizada, os índices de analfabetismo, a defasagem na relação idade/série), notadamente no ensino fundamental.

O fato é que, de acordo com a autora, ainda convivemos com problemas como evasão de crianças e jovens das escolas, descompasso idade/série, baixa qualidade de ensino e o não domínio pelos estudantes de aprendizagens fundamentais.

Após um ano de interrupção dos estudos, Helena voltou a estudar em uma escola pública municipal recém-construída em seu bairro. Fez um teste de seleção para o ingresso, exigido pela instituição, e foi vitoriosa. Apesar das queixas contra as regras rigorosas da escola, percebe-se em seu relato a descrição de bons momentos vividos ali. As turmas eram separadas pelo nível de rendimento dos alunos, procedimento muito comum no País na década de 1970. Alguns docentes foram relembrados com carinho pela aluna.

Alguns professores, como Dona Dóris, que lecionava Português, Cândido de Ciências, Afra de História, ficarão guardados para sempre no meu coração. Dóris era fantástica, trabalhava com os alunos sempre em grupos. Cândido era muito brincalhão, abria sapos e outros bichos, foi o primeiro amor platônico da minha vida. Afra me levava a viagens fantásticas por outros mundos, culturas e ideias. Sinto saudades dessa fase da minha vida. Sei o quanto foram importantes todas as experiências ali vivenciadas. Hoje a escola encontra-se sucateada, abandonada, num estado de fazer dó. 
Diversos estudos que tratam do sucesso escolar de alunos das camadas desfavorecidas, como os de Laurens (1992), Portes (2003) e Viana (2007), revelam que, de maneira geral, a escolaridade bem-sucedida nos níveis iniciais é um dos fatores que concorrem para um percurso vitorioso. Apesar de um início problemático em sua trajetória escolar, Helena conseguiu, talvez por esforço próprio e pela ajuda de bons professores, seguir em frente e não abandonar o estudo nas séries iniciais, fato muito comum em relação às classes populares no Brasil na época retratada. Chama a atenção no percurso escolar da aluna sua persistência e coragem, pois não abandonou a escola, mesmo após o conselho de que interrompesse os estudos, proferido por sua professora na primeira instituição em que se matriculou na capital. Esses golpes, no início da escolaridade, são cruéis, pois sabemos a força que os veredictos escolares exercem sobre os indivíduos.

Em 1977, Helena ingressou em uma escola municipal de Belo Horizonte bastante conceituada na época, mas, como precisava trabalhar, foi obrigada a transferir-se para outro colégio e estudar à noite. Os três anos do atual ensino médio foram, portanto, conciliados com o trabalho no comércio, fato bastante comum nas trajetórias escolares de indivíduos pertencentes às classes populares. Percorridos esses anos de estudo, foi obrigada novamente a interromper sua trajetória escolar, pois seu pai adoecera e ela assumiu financeiramente as responsabilidades pela família. Dessa forma, o sonho de cursar o ensino superior ficava cada vez mais distante.

\section{O curso de Magistério e a primeira experiência como professora}

Seis anos após a conclusão do ensino médio, Helena resolveu fazer um curso intensivo de Magistério. É importante destacar que a aluna não mencionou o "espírito de vocação", que aparece em vários estudos sobre os professores - como na pesquisa realizada por Mello (1998) - quando são indagados sobre os motivos da escolha da profissão.

No ano de 1986, fiz no colégio Minas Gerais um curso intensivo de Magistério. Meu primeiro filho tinha três anos, eu procurava uma maneira de poder acompanhá-lo durante sua escolarização. Essa experiência tinha um caráter somente cultural, jamais pensava em ser professora. Em primeiro lugar, o salário de telefonista era melhor que o dos professores; em segundo, eu gostava muito da minha profissão. Após alguns anos, tive meu segundo filho, o salário como telefonista já não estava compensador e, encorajada por meu marido, deixei a Telemig e iniciei a carreira de educadora.

$\mathrm{O}$ acaso permitiu que ela iniciasse a profissão de professora, pois uma amiga formada em Pedagogia a convidou para abrir uma escola. Sua primeira experiência como docente foi com uma turma do maternal e, nos anos subsequentes, procurou sempre inovar em sua atividade. Ao observar o trabalho de outras professoras que lecionavam em sua escola, percebeu como exerciam o seu ofício superficialmente. Segundo ela, as docentes colocavam em prática "uma didática muito técnica". No entanto, 
ao questionar a prática pedagógica das colegas, teve consciência de que sua atuação como professora não era diferente. Dessa forma, resolveu buscar um conhecimento mais aprofundado para exercer melhor o ofício. A procura foi reforçada por seu pai, que, antes de morrer, aconselhou a filha a continuar os estudos.

Apesar de a aluna ater-se pouco às relações familiares em seu memorial, emerge de sua narrativa uma questão relevante acerca das famílias dos meios populares. Lahire (1997) revela-nos, nas pesquisas que realizou sobre o sucesso escolar nesses meios, como há desconhecimento acerca dessas famílias, tomadas em diversos estudos como se fossem homogêneas. O autor mostra-nos em seu trabalho a existência de pais que, mesmo analfabetos ou de baixa escolaridade, valorizam e incentivam o estudo de seus filhos, sacrificando-se para que eles alcancem a longevidade escolar. Essa imagem da classe desfavorecida revelada por Lahire contradiz o senso comum, que tende a sustentar uma visão preconceituosa acerca desses sujeitos, como a de que todos esses pais são relapsos em relação à educação escolar das crianças. O pai de Helena, segundo ela, aparentemente não se interessava muito pelos estudos de seus filhos, mas deve ter percebido o potencial da filha. Daí o conselho tardio, mas que foi fundamental para que ela continuasse sua trajetória escolar.

\section{A formação acadêmica}

No que diz respeito à formação acadêmica, Helena preferiu refletir junto a uma colega de classe - à qual se deu o nome de Sandra - em virtude da semelhança entre suas trajetórias escolares e profissionais. A escolha do curso Normal Superior por essas alunas partiu de uma decisão consciente. Elas procuravam respostas para indagações advindas de suas práticas como professoras. Assim como acontecera com Helena, que teve um início de escolaridade frustrante, Sandra foi reprovada três vezes na primeira série por uma professora leiga, Dona Dionízia. As imagens dessas professoras nunca abandonaram as duas e o temor de repeti-las em seus ofícios emerge das escritas tecidas por elas. Segundo Tardif (2002, p. 273), um dos erros que mais comprometem o magistério tem origem em um problema epistemológico do modelo universitário de formação, que "trata os alunos como espíritos virgens e não leva em consideração suas crenças e representações anteriores a respeito do ensino". O autor defende, inclusive, que a formação em um curso superior surte pouco efeito sobre as crenças dos docentes construídas anteriormente.

Outro autor que nos fornece pistas sobre o professor e seu trabalho é Nóvoa (1992), que ressalta a importância de se conhecerem as dimensões pessoais e profissionais do professor, pois sua ação pedagógica é influenciada por suas características pessoais e por seu percurso de vida profissional. Segundo o autor, durante muito tempo, até a década de 1980, essas dimensões não eram contempladas nos estudos pedagógicos, que concentravam suas atenções exclusivamente sobre as práticas de ensino. 
O interesse pela vida e pela pessoa do professor é, portanto, recente. "A maneira como cada um de nós ensina está diretamente dependente daquilo que somos como pessoa quando exercemos o ensino" (Nóvoa, 1992, p. 17).

A respeito das considerações feitas por Tardif e Nóvoa, avalio como é importante para os educadores que trabalham com a formação de professores conhecerem os alunos e suas histórias pessoais e escolares, e acredito que o memorial constitui-se em excelente instrumento para tornar isso possível. Ao recordar o início do curso e as primeiras aulas, as alunas falam principalmente das grandes dificuldades encontradas no entendimento e uso da linguagem acadêmica e, nas palavras delas, da "precariedade dos conhecimentos que havíamos acumulado".

Bourdieu (2006) procura romper, em sua obra, com o velho dilema do subjetivismo ou objetivismo, que perpassa as Ciências Sociais, propondo como alternativa uma teoria da prática que teria como elemento fundamental o conceito de habitus, que, segundo o autor, consiste em:

[...] sistemas de disposições duráveis, estruturas estruturadas predispostas a funcionar como estruturas estruturantes, isto é, como princípio gerador e estruturador das práticas e das representações que podem ser o produto da obediência a regras, objetivamente adaptadas a seu fim sem supor a intenção consciente dos fins e o domínio expresso das operações necessárias para atingi-los e coletivamente orquestradas, sem ser o produto da ação organizadora de um regente. (Bourdieu, 2006, p. 53-54).

O habitus seria substancialmente influenciado pela posição do indivíduo na estrutura social. Seus gostos, crenças, maneiras de pensar, agir e até mesmo de se vestir estariam fortemente atrelados a sua condição social e cultural. A família e a escola, responsáveis pelas socializações primária e secundária, são instituições fundamentais na formação do habitus. No entanto, esse conjunto de disposições teria certa flexibilidade, pois, ao longo da vida, elas estariam sujeitas a adaptações às diversas experiências vivenciadas pelo indivíduo. Portanto, para o autor, as ações dos sujeitos não seriam completamente autônomas, nem determinadas de forma mecânica pelas estruturas econômicas e sociais.

Na escrita de Helena, de Sandra e de outras alunas que orientei percebe-se claramente o choque inicial com o habitus dos professores e as mudanças nas próprias disposições das discentes. A maneira de pensar, as crenças, os gostos e a linguagem sofrem modificações visíveis no decorrer do percurso acadêmico. Logicamente, não é possível afirmar que essas mudanças se devem unicamente às vivências nesse espaço, de modo que somente com base em um aprofundamento acerca da questão é possível fundamentar tais observações. ${ }^{2}$

Helena, Sandra e outras alunas relataram, em seus memoriais, uma substancial mudança ocorrida em suas práticas docentes a partir do ingresso no curso superior.

Essa contribuição do curso Superior na nossa vida, tanto profissional como pessoal tem sido de fundamental importância para mudanças de Para um aprofundamento
dessa questão, ver estudo
que utiliza a história de vida
como metodologia, com quatro
professoras egressas do curso
Normal Superior (Dias, 2010). 
atitude. Hoje não somos mais as mesmas professoras, o nosso olhar tornou-se mais analítico, estamos mais conscientes e preparadas para enfrentar e identificar situações existentes nessa teia de relações que é a educação. Nesse processo de formação profissional, temos como desafio entender a articulação entre a teoria e a prática na nossa formação como profissional. Acreditamos que somos capazes de olhar nossos fazeres educativos, realizar escolhas amparadas teoricamente no prazer de ensinar e de aprender, diminuindo o risco de repetir os mesmos erros de práticas pedagógicas.

Em relação às práticas pedagógicas e à constituição da identidade docente, a que as professoras fazem menção ao analisarem em seus memoriais a influência do Curso Normal Superior em sua prática docente, há um importante estudo realizado por Gauthier et al. (1998) que nos ajuda a compreender melhor essas categorias. Os autores analisaram uma extensa literatura resultante de pesquisas efetuadas por vários estudiosos que tentaram estabelecer um "repertório de conhecimentos" que correspondesse aos saberes profissionais próprios ao professor. Para eles:

[...] as inúmeras pesquisas realizadas nos últimos anos, com o objetivo de definir um repertório de conhecimentos para a prática pedagógica, podem ser interpretadas como uma série de incentivos para que o docente se conheça enquanto docente, como uma série de tentativas de identificar os constituintes da identidade profissional e de definir os saberes, as habilidades e as atitudes envolvidas no exercício do magistério. (Gauthier et al., 1998, p. 18).

Os autores identificam os seguintes saberes necessários ao ensino: disciplinar, curricular, das ciências da educação, da tradição pedagógica, experiencial e da ação pedagógica, que "é o saber experiencial dos professores, a partir do momento em que se torna público e que é testado por meio das pesquisas realizadas em sala de aula" (Gauthier et al., 1998, p. 33), em cuja tentativa de revelação os pesquisadores concentraram seus esforços. Também foram analisadas várias pesquisas sobre a prática dos professores em sala de aula e o resultado surpreende pela riqueza e variedade de saberes que envolvem o exercício do magistério.

Marcelo (1998), ao apresentar uma síntese sobre as pesquisas acerca da formação de professores, nos diz, baseado nos trabalhos realizados por Zeichner e Gore (1990 apud Marcelo, 1998), que a influência dos cursos acadêmicos na mudança das crenças dos professores em formação é limitada e pouco conhecida e que as ideias iniciais que esses docentes possuem, anteriores a essa formação, tendem a persistir. A leitura dos memoriais trouxe-me informações diferentes em relação às mudanças ocorridas tanto nas crenças como nas práticas docentes. No entanto, como essas alunas que orientei estavam finalizando um curso de quatro anos, a influência deste em suas vidas, nos aspectos pessoal, escolar e profissional, era sentida com intensidade. Será que com o passar dos anos e o distanciamento do curso essa influência persistirá? Para responder a essa questão penso que novas pesquisas se fazem necessárias. 
Na instituição em questão, os estágios, que constituem uma etapa importante na formação dos alunos, eram realizados nos $6^{\circ}, 7^{\circ}$ e $8^{\circ}$ períodos. Os discentes observavam as aulas dos professores, faziam diversos registros sobre as estruturas física e funcional das escolas e elaboravam um projeto de intervenção com o objetivo de sanar ou amenizar alguma dificuldade sentida pela turma, em acordo com o professor supervisor. As observações de Helena sobre os estágios vivenciados são, de maneira geral, de desagrado em relação às posturas dos professores supervisores e outros profissionais diante do conhecimento e das interações com os alunos.

Do ponto de vista metodológico ficava evidente um modelo burguês de educação. Os conteúdos desconectados das vidas dos alunos. Não havia uma relação entre o que as professoras ensinavam e o que os alunos viviam. As professoras apresentavam-se como as que tinham a responsabilidade de transmitir os conhecimentos aos alunos; e estes, os que tinham a obrigação de aprender. Dessa forma, quanto mais autoritário era o professor, mais a comunidade escolar o considerava bom, capaz de ordenar e disciplinar a turma.

Apesar do encontro com profissionais que a desagradaram profundamente, Helena aponta como pontos positivos o desenvolvimento dos projetos de intervenção - apesar do pouco tempo para sua aplicação -, os conhecimentos teóricos que adquiriu para compreender melhor os contextos educacionais encontrados e a reflexão sobre a própria prática como docente.

\section{Conclusão}

Nos últimos anos houve um aumento de estudantes pertencentes às classes populares em cursos destinados a formar professores da educação básica. Como formadores de professores, precisamos conhecer melhor esses sujeitos, suas histórias pessoais e escolares. Penso que as faculdades de educação devam se dirigir a um professor real, levando em consideração seus pertencimentos de classe, de gênero e étnico-racial. As narrativas feitas pelas professoras em seus memoriais, descrevendo suas trajetórias escolares, nos trazem importantes informações sobre lacunas em suas formações. Tais informações são valiosas para que possamos, como professores atuantes em cursos de formação de docentes, construir práticas curriculares que preencham esses vazios.

Os pais dessas professoras, de acordo com os relatos que fizeram em seus memoriais, possuem um reduzido capital cultural e econômico e não puderam propiciar a elas vivências culturais consideradas legítimas e diferentes daquelas existentes em seu meio social. Por sua vez, as docentes revelaram, também nesses trabalhos, que as escolas que frequentaram não se preocupavam em proporcionar a seus alunos esse tipo de vivência cultural. Portanto, os cursos de licenciatura precisam preencher essa e outras lacunas para que possam contribuir para a formação de professores que atuem com a qualidade julgada necessária. 
Assim como Gauthier et al. (1998), acredito que existe um saber próprio ao ensino e que não basta ter talento, bom senso ou seguir a intuição para ser um bom professor. Em algumas das narrativas dos memoriais, as alunas afirmam que defendiam, ao iniciarem o curso Normal Superior, tais crenças sobre como exercer bem o magistério.

Os autores utilizam a expressão "ofício sem saberes" para identificar a situação problemática em que se encontra a profissão de professor. No entanto, para estes, "a tendência inversa também existe, ou seja, a de formalizar o ensino, mas reduzindo de tal modo sua complexidade, que ele não mais encontra correspondente na realidade" (Gauthier et al., 1998, p. 25-26). Pode-se, assim, resumir essa situação por meio de outra expressão utilizada pelos autores: "saberes sem ofício". As faculdades de educação produziram saberes formalizados baseando-se em algumas pesquisas, mas "esses saberes não se dirigiam ao professor real, cuja atuação se dá numa verdadeira sala de aula, mas a uma espécie de professor formal, fictício, que atua num contexto idealizado, unidimensional, em que todas as variáveis são controladas". Para esses estudiosos, é preciso evitar estes dois erros: "um ofício sem saberes" e "saberes sem ofício", e caminhar, vencendo o desafio da profissionalização rumo "à construção de um ofício feito de saberes".

Para finalizar este artigo, gostaria de ressaltar que as experiências escolares que emergem do memorial de Helena e de outras alunas que orientei nos dão um panorama rico e interessante sobre as histórias vividas por esse grupo de professoras-estudantes e nos ajudam, a meu ver, a vislumbrar um pouco mais a relação entre as subjetividades dos docentes - marcadas por histórias pessoais e escolares e pelo saber experiencial conquistado no cotidiano profissional - e o possível impacto cultural em suas práticas, proporcionado pelo caminho percorrido em um curso superior de formação de professores.

Em todos os memoriais há uma reflexão sobre o impacto proporcionado pela vivência no curso Normal Superior, no sentido de que este foi responsável por mudanças na vida pessoal e profissional dessas professoras. Como já foi dito neste trabalho, resta saber se esse efeito é duradouro em suas trajetórias como docentes. Vejo, com pesar, que esses relatos revelam um mundo desconhecido por grande parte dos professores que lecionam nos cursos de formação de docentes. O trabalho com memoriais pode ajudar na reflexão dos discentes sobre suas trajetórias escolares e pessoais e ainda sobre suas práticas docentes, no caso dos alunos-professores, e a constituir sua identidade docente. Segundo Souza (2008, p. 91), "quem narra e reflete sobre sua trajetória abre possibilidades de teorização de sua própria experiência e amplia sua formação através da investigação e formação de si".

Portanto, acredito que essa modalidade de trabalho deva ser cada vez mais incentivada nos cursos que se destinam a formar docentes. Os memoriais elaborados pelos discentes, além de contribuir para ampliar o conhecimento sobre os estudantes, permitem aos professores que atuam nesses cursos compreender melhor o ofício de professor e, sobretudo, reorientar suas práticas curriculares. 


\section{Referências bibliográficas}

BOURDIEU, P. Escritos de educação. Organizado por Maria Alice Nogueira e Afrânio Catani. Petrópolis: Vozes, 1998.

BOURDIEU, P. A economia das trocas simbólicas. São Paulo: Perspectiva, 2003.

BOURDIEU, P. Sociologia. Organizado por Renato Ortiz. São Paulo: Olho D'Água, 2006.

BOURDIEU, P. A distinção: crítica social do julgamento. São Paulo: Ed.

Usp, 2007.

DIAS, R. L. C. Repercussões da formação em nível superior nas práticas pessoais e profissionais das camadas populares. 2010. Tese (Doutorado em Educação) - Faculdade de Educação, Universidade Federal de Minas Gerais, Belo Horizonte, 2010.

FORQUIN, J. C. (Org.). Sociologia da educação: dez anos de pesquisa. Petrópolis: Vozes, 1995.

GAUTHIER, C. MARTINEAU, S.; DESBIENS, J.; MALO, A.; SIMARD, D. Por uma teoria da Pedagogia: pesquisas contemporâneas sobre o saber docente. Ijuí: Unijuí, 1998.

HOULE, G. A sociologia como ciência da vida: a abordagem biográfica. In: POUPART, J.; DESLAURIES, J. P.; GROULX, L. H.; LAPERRIËE, A.; MAYER, R.; PIRES, A. P. A pesquisa qualitativa: enfoques epistemológicos e metodológicos. Petrópolis: Vozes, 2008. p. 317-336.

LAHIRE, B. Sucesso escolar nos meios populares. São Paulo: Ática, 1997.

LAURENS, J. P. I sur 500: la reussite scolaire em milieu populaire.

Toulouse: Presses Universitaires du Mirail, 1992.

MARCELO, C. Pesquisa sobre a formação de professores: o conhecimento sobre aprender a ensinar. Revista Brasileira de Educação, Rio de Janeiro, n. 9, p. 51-75, set./dez. 1998.

MELLO, G. N. Magistério de $1^{\circ}$ grau: da competência técnica ao compromisso político. 12. ed. São Paulo: Cortez, 1998.

NÓVOA, A. (Org.). Vidas de professores. Porto: Porto Editora, 1992.

PORTES, E. A. Trajetórias escolares e vida acadêmica do estudante pobre da UFMG: um estudo a partir de cinco casos. 2001. Tese (Doutorado 
em Educação) - Faculdade de Educação, Universidade Federal de Minas Gerais, Belo Horizonte, 2003.

ROMANELLI, O. de O. História da educação no Brasil. Petrópolis: Vozes, 2007.

SOUZA, E. C. de. Modos de narração e discursos da memória: biografização, experiências e formação. In: PASSEGI, M. da C.; SOUZA, E. C. de. (Auto)Biografia: formação, territórios e saberes. Natal: Ed. UFRN; São Paulo: Paulus, 2008. p. 85-101.

TARDIF, M. Saberes docentes e formação profissional. Petrópolis: Vozes, 2002.

THOMPSON, P. A formação da classe operária inglesa. Rio de Janeiro: Paz e Terra, 1987.

VIANA, M. J. B. Longevidade escolar em famílias populares: algumas condições de possibilidade. Goiânia: Ed. UCG, 2007.

ZAGO, N. Quando os dados contrariam as previsões estatísticas: os casos de êxito escolar nas camadas socialmente desfavorecidas. Paidéia, Ribeirão Preto, v.10, n. 8, p. 70-80, jan./jul. 2000.

ZAGO, N. A relação escola-família nos meios populares: apontamentos de um itinerário de pesquisas. In: DAYRELL, J.; NOGUEIRA, M. A.; RESENDE, J. M.; VIEIRA, M. M. (Org.). Família, escola e juventude: olhares cruzados Brasil-Portugal. Belo Horizonte: Ed. UFMG, 2012. p. 132-150.

Recebido em 15 de dezembro de 2014.

Solicitação de correções em 27 de maio de 2015.

Aprovado em 16 de junho de 2015. 